\title{
Development of a Heavy-Loaded Hydrodynamic Slide Bearing for a Reducer for a Turbojet Dual Engine
}

\author{
Silchenko Olga Borisovna*, Siluyanova Marina Vladimirovna \\ Department of Technology of Production and Operation of Aircraft Engines, Institute №12 MAI (National Research University), Moscow, \\ Russia
}

Email address:

silyaolya@yandex.ru (S. O. Borisovna),dc2mati@yandex.ru (S. M. Vladimirovna)

${ }^{*}$ Corresponding author

\section{To cite this article:}

Silchenko Olga Borisovna, Siluyanova Marina Vladimirovna. Development of a Heavy-Loaded Hydrodynamic Slide Bearing for a Reducer for a Turbojet Dual Engine. American Journal of Engineering and Technology Management. Vol. 4, No. 4, 2019 , pp. 66-72.

doi: 10.11648/j.ajetm.20190404.11

Received: March 19, 2019; Accepted: June 26, 2019; Published: November 19, 2019

\begin{abstract}
The object of the design is a heavy-loaded hydrodynamic slide bearing for the reducer for a turbojet bypass engine (TJBE) of a new generation for the near-medium-haul main plane (NMHMP) of civil aviation. The aim of the work is to produce working design documentation (WDD) for sliding bearings with anti-friction coatings based on metal polymers, porcelain polymers, composite materials using quasicrystals and developing variants of design and structural schemes for using sliding bearings with anti-friction coatings based on metal polymers, ceramic ceramics or composite materials with using quasicrystals in satellites (gears) of fan reducers of the family are promising TJBE for NMHMP. Designed bearings are designed for use as supports for the intermediate gears of the gearbox, made according to the kinematic scheme "Star". Based on the calculations, the design of the sliding bearing was determined and the WDD was produced for four bearings of the same size with different antifriction coatings used as supports for intermediate gears of the designed TJBE for NMHMP. But, as experience shows, in order to successfully work out the parameters of promising heavily loaded hydrodynamic sliding bearings, a close relationship is needed between the calculated estimate and its experimental verification (while perfecting the tools and methods of both). As a result of this work, WDD was produced for sliding bearings with anti-friction coatings based on metal polymers, ceramic ceramics (silicon carbide, titanium diboride) with and without quasicrystals and composite materials (titanium carbonitride, silicon carbonitride) with and without quasicrystals.
\end{abstract}

Keywords: Gearbox, Slide Bearing, Anti-Friction Coating, Ion-Vacuum Method, Detonation Method, Hydrodynamic Lubrication Mode, Mounting Radial Clearance, Pressure Diagram

\section{Introduction}

Currently, new engine families are being developed in Russia and abroad in the range of $88290 \ldots 176580$ N. These engines can be installed on various types of aircraft, including the most popular new single-bodied NMHMP (with one pass for passengers).

A draft design of an experimental fan drive reducer was developed for a new generation of competitive turbofan engines. The kinematic scheme of the developed gearbox is made according to the scheme, where the radial plain bearings operating in fluid friction mode are supports of circumferential intermediate gears. With proper construction and lubrication, the sliding bearings can carry heavy loads at high sliding speeds. They have small radial dimensions and mass. The big advantage of sliding bearings is noiselessness at work and high damping ability under the influence of cyclic and shock loads. The durability of the sliding bearings does not depend on the sliding speed (unlike rolling bearings, the durability of which decreases in proportion to the increase in the speed of rotation).

In the period from the middle of the last decade of the twentieth century to the present, heavily loaded hydrodynamic sliding bearings with various anti-friction coatings have been actively developed for use as satellite (intermediate) gears supports in gearboxes for turbofan engines with a high degree of bypass ratio with a bronzofluoroplastic coating. [1,2]. 
In this work, we investigate and analyze the performance of engineered plain bearings of the same size with various anti-friction coatings, as well as a bearing with a bronzofluoroplastic coating of the same size, used as intermediate gear supports, designed gearbox TJBE for NMHMP.

The object of the design is a sliding bearing based on metal polymers, ceramic polymers, composite materials using quasicrystals. [3-6].

Designed sliding bearings are designed for Zvezda-type gearboxes with spur gears or chevron gears, where they are used as supports of equidistant circumferential gears of the turbofan gearbox of the new generation. These bearings can also be used in other industries in a wide range of working (operational) loads.

Bushing (intermediate gear reducer) mounted in the bearing with a gap in accordance with Figure 1a, Under the action of a constant load occupies an eccentric position; on both sides of the point of closest approach of the sleeve and the bearing, the gap takes the form of a wedge-shaped slot. Rotating, the sleeve carries with it the oil. The first layer of oil wetting the sleeve is carried away due to the adsorption of oil on the metal surface of the sleeve, the subsequent layers due to the internal viscosity of the oil. The sleeve thus acts as a pump, which injects oil into the wedge-shaped gap.

When entering a gap narrowing in the direction of rotation of the sleeve, the oil, which is a practically incompressible fluid (at normal pressures in the bearing), tends to spread in the circumferential and axial directions (to the ends of the bearing). This is prevented by viscous forces, as a result of which pressure builds up in the oil layer, progressively increasing to the point of closest approach between the sleeve and the bearing, where the oil outflow is hindered due to the small gap (Figure 1b).

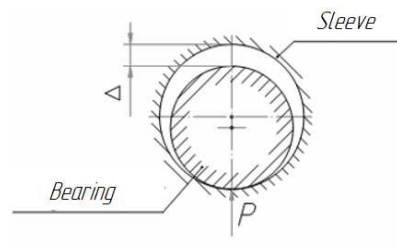

a)

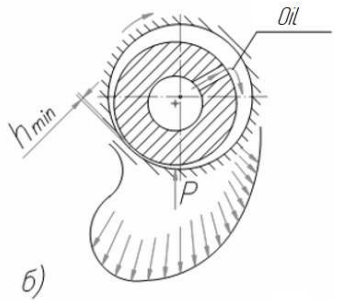

6)
In case of liquid friction, the surfaces of the sleeve and bearing are separated by a continuous oil film; there is no direct friction between the sleeve and bearing surfaces.

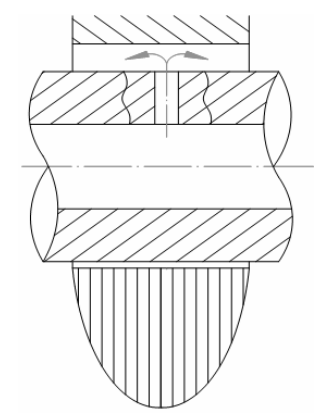

Figure 2. The pressure in the oil layer along the axis of the bearing.

\section{Features of the Bearing Design}

All four plain bearings are designed taking into account the results of hydrodynamic and strength calculations. All bearings are interchangeable (one size) and differ only in the type of antifriction coatings and the method of their application. In addition, for structural and technological reasons, the bearing bush with bronze-fluoroplastic coating is made of EP-693 VD alloy.

To increase the wear resistance of sliding bearing trunnions, a nitride-titanium coating is applied to their surfaces.

Limit deviations of the sizes, shape and location of the surfaces of sliding bearings with anti-friction coatings are assigned, based on the results of hydrodynamic calculations and accumulated experience in the design, manufacture and testing of sliding bearings. [7-9]

The parameters of the bearings were evaluated by analyzing the Navier-Stokes equations for lubricant flow in the bearing gap with defining end leaks $[1,2]$, which, when used at the plant, used the design, technology and the degree of loading of the bearings, gave a fairly accurate assessment consistent with the results of testing on a special stand for testing bearings.

An example of the peak pressures calculated by this method and measured at the facility in the meridional section of the bearing and pumping oil through the bearing is shown in Figure 3.

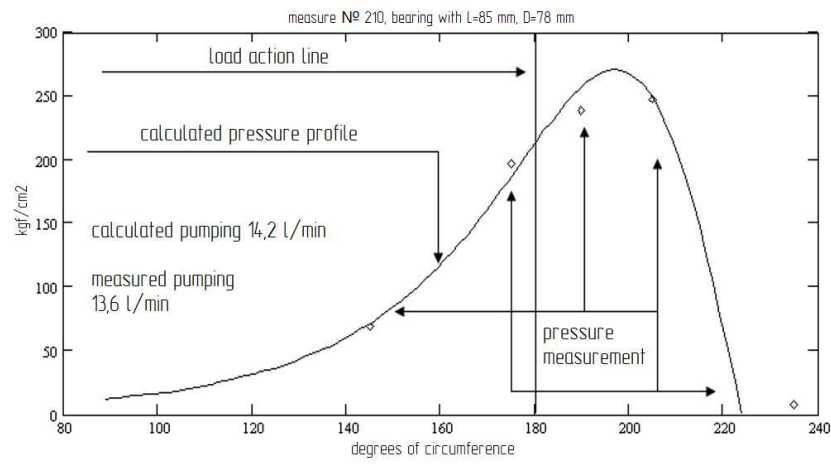

Figure 3. Scanning of the calculated peak pressure profile in the meridional section of the bearing and measurement of peak pressure and oil pumping at the installation.
Part of the oil flows through the ends of the bearing and in the direction opposite to the movement of the sleeve; the rest should go through the narrowest point of the gap. The pressure forces developing in the oil layer raise the sleeve, at the same time shifting it in the direction of rotation. The state of equilibrium is reached when the flow area at the narrowest point of the gap $\left(h_{\min }\right)$ is sufficient to allow the oil to pass through the face flow.

The pressure in the oil layer along the axis in a cylindrically correct bearing varies along a parabolic curve (Figure 2), it drops sharply at the ends of the bearing as a result of oil outflow through the ends. 


\section{Method for Estimating Bearing Parameters}

The calculation scheme of the hydrodynamic sliding support is shown in figure 4 .

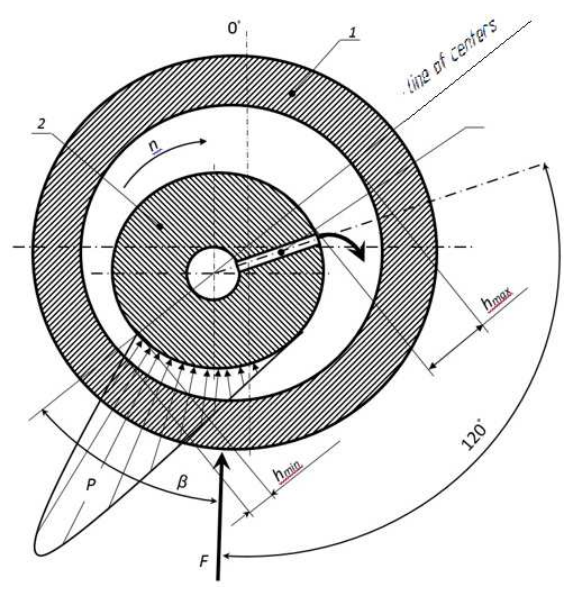

Figure 4. Calculation scheme for hydrodynamic slide bearing.

\section{The Results of the Calculation of Bearings with Bronze-Fluoroplastic Coating}

Scanning on the plane of the calculated epure of oil pressure in the bearing gap with a bronze-fluoroplastic coating is shown in Figure 5.

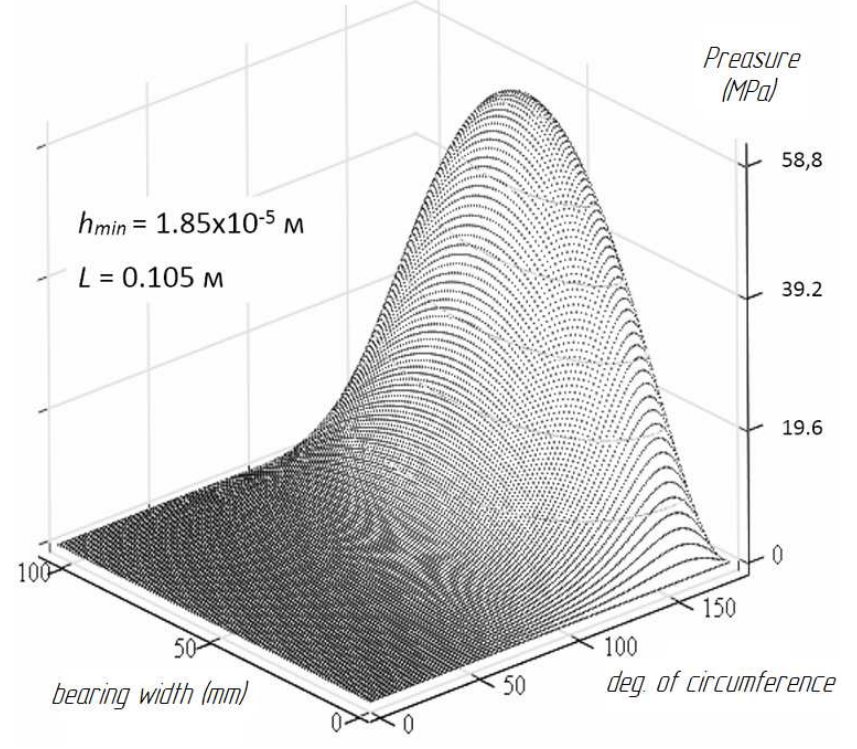

Figure 5. Scanning the plot of oil pressure in the bearing gap.

The parameters of the intermediate gear bearing with bronze-fluoroplastic coating, calculated for the variant of the NMHMP motor gearbox with five intermediate gears, and manufactured at the enterprise of such bearings are shown in accordance with Table 1.

Table 1. Parameters of bearings.

\begin{tabular}{|c|c|c|c|}
\hline & Intermediate Gear Bearing & Bearing for firm SNECMA & Bearing for gearbox $\mathrm{KV}$ \\
\hline Length $(L), \mathrm{mm}$ & 105 & 145 & 85 \\
\hline Diameter $(d), \mathrm{mm}$ & 85 & 100 & 78 \\
\hline The ratio of length to diameter $(L / d)$. & 1,235 & 1,45 & 1,1 \\
\hline Radial clearance $\left(C_{m}\right), \mu \mathrm{m}$ & 63,75 & 74,5 & 80,5 \\
\hline The ratio of the radial clearance to the radius $\left(C_{m} / r\right) \ldots$ & 0,00150 & 0,00149 & 0,00206 \\
\hline The angle of oil supply $(a l),{ }^{\circ} \mathrm{C} \ldots$ & 120 & 120 & 110 \\
\hline Oil grade & MJO-II & MJO-II & ИПМ-10 \\
\hline Rotation frequency $(n), \min ^{-1}$ & 11110 & 11450 & 13720 \\
\hline Sliding speed $(\mathrm{u}), \mathrm{m} / \mathrm{s}$. & 49,45 & 59,89 & 56,03 \\
\hline Oil temperature at the inlet (tbx), ${ }^{\circ} \mathrm{C} .$. & 100 & 100 & 98 \\
\hline The level of viscosity of the heated oil (tbix), ${ }^{\circ} \mathrm{C}$ & 118,01 & 118,99 & 107,7 \\
\hline The temperature of the beginning of turbulence $(\mathrm{tkr}),{ }^{\circ} \mathrm{C}$ & 131,5 & 110,35 & 100,78 \\
\hline Average unit load (pm), MPa ... & 15,69 & 16.92 & 11.08 \\
\hline Specific power of boundary friction $(\mathrm{Nr}), \mathrm{kW} / \mathrm{cm}^{2} \ldots$ & 0,854 & 1,115 & 0,683 \\
\hline Maximum pressure in the lubrication layer $(\mathrm{P}), \mathrm{MPa}$. & 60.80 & 60.80 & 53.94 \\
\hline Minimum operating clearance (hmin), $\mu \mathrm{m}$ & 18,56 & 24,59 & 15,52 \\
\hline Viscous friction losses $(\mathrm{N}), \mathrm{kW}$ & 8,162 & 16,07 & 4,791 \\
\hline Required oil pumping (q), $\mathrm{m}^{3} /$ hour.. & 0.592 & 0.8556 & 0.942 \\
\hline Arc lubrication (TE), ${ }^{\circ}$ & 158,1 & 161,1 & 139,93 \\
\hline The stiffness of the layer of oil (dwdh), N/ $\mu \mathrm{m}$ & 16367 & 21967 & 9914 \\
\hline
\end{tabular}

\section{Selection of Criteria Values for Bearing Parameters}

When designing bearings with a given loading $(w, n)$ and optimal exhaust angle of lubrication $(a l)$ and the ratio of the mounting gap to the radius $\left(C_{m / r}\right)$, the constraint determined by experimental values for the maximum values of the following bearing criteria was taken into account (in the development of this design, manufacturing technology and operation of the bearing): 
1. maximum peak pressure in the lubricant layer $\left(P_{\max }=60.80 \mathrm{MPa}\right)$;

2. minimum working clearance in the bearing $\left(h_{\min }=15\right.$ $\mu \mathrm{m})$

3. ratio of load bearing $\left(S_{0}=29,2\right)$;

4. the mode of lubricant flow in the bearing (laminar, initial turbulence);

5. average specific load $\left(p_{m}=16.93 \mathrm{MPa}\right)$;

6. specific power of boundary friction $\left(N_{r}=1,115 \mathrm{~kW} / \mathrm{cm}^{2}\right)$;

7. arc length lubrication $\left(\mathrm{Te}<180^{\circ}\right)$;

8. the level of critical frequencies of the sleeve on the lubricant layer.

For the bearing of the intermediate gear of the NMHMP motor reducer (in the variant with five intermediate gears) the maximum limitation was the maximum peak pressure of 60 - $80 \mathrm{MPa}$.

In used bearings, the achieved minimum operating clearance $\left(h_{\min }\right)$, which guarantees the hydrodynamic lubrication mode, was $15.52 \mu \mathrm{m}$ (bearing for the " $\mathrm{KV}$ " reducer), which could be provided structurally and technologically during the design and manufacture of bearing parts, and operational when testing it at the installation and operation as part of the product.

Technologically and operationally provided minimum working gap of the hydrodynamic lubrication mode is determined in accordance with the formula

$$
h_{m i n}=H_{\mathrm{sp}}+H_{\mathrm{sl}}+h_{\mathrm{sp}}+h_{\mathrm{sl}}+h_{\mathrm{s} / \mathrm{f}}-h_{\mathrm{pr} .}-h_{\mathrm{absorb} .} \mu \mathrm{m}
$$

when:

$H_{\mathrm{sp}}-$ spike non-cylindrical $(035 \mu \mathrm{m})$,

$H_{\mathrm{sl}}$ - non-cylindrical sleeves $(03 \mu \mathrm{m})$,

$H_{\text {sp }}-$ spike microroughness $(01,25 \mu \mathrm{m})$,

$H_{\text {sl }}$ - sleeve microroughness $(00,16 \mu \mathrm{m})$,

$H_{\mathrm{s} / \mathrm{f}}-$ size of oil filter cells $(16 \mu \mathrm{m})$,

$H_{\text {pr. }}$ - amount of maximum possible leveling of macro- and microroughness of the surface layer during running-in,

$H_{\text {absorb. }}$ - maximum solids that the surface layer is able to absorb.

$H_{\text {pr. }}+h_{\text {absorb }}-$ on the bronze-fluoroplastic coating was determined by the thickness of the layer of pure fluoroplastic $(15 \ldots 25 \mu \mathrm{m})$ ).

For used designs of sliding bearings, the technologically and operationally provided minimum working gap is at nominal tolerances for bearing production and oil filtration degree of $15 \mu \mathrm{m}$.

The use of the proposed materials for anti-friction coatings on the bearing surfaces of the bearings can expand the limits of the bearing operability due to other parameters that determine the minimum working gap in the bearing and the maximum working pressure in the oil layer that is allowed for the guaranteed hydrodynamic lubrication mode. [11]

Taking into account the expansion of the boundaries of the bearings with coatings from the proposed antifriction materials by reducing the minimum working gap and increasing the maximum peak pressure in the lubricant layer of bearings, the bearing parameters were estimated in the dimensions of the bearing of the intermediate gear of the engine gearbox for NMHMP.

A number of minimum working clearances were adopted for the technological and operational parameters: $18.5 \mu \mathrm{m}, 15$ $\mu \mathrm{m}, 12 \mu \mathrm{m}$ and $10 \mu \mathrm{m}$, and the parameters of the bearings were calculated under loading corresponding to the maximum take-off mode for the bearing in the dimensions of the intermediate gear of the NMHMP motor reducer for five and six intermediate gears), and also estimated the impact of the possibility of reducing the technologically and operationally provided minimum working gap and simultaneously increasing the maximum yes Lenia a lubricating layer to reduce the axial dimensions of the bearing, which is important when the gear arrangement for optimizing the weight, dimensions and strength characteristics.

When developing the previously manufactured plain bearings, the assembly radial clearances in the bearings, and, consequently, the corresponding all other bearing parameters, were finally specified after the bench tests of the bearings.

\section{The Results of the Calculation of Bearings with Anti-friction Coatings}

In the following evaluation of the parameters of bearings with different minimum working clearances and the corresponding maximum pressures in the lubricant layer, the amount of lubricant pumped through the bearing was kept constant with changes in the operating bearing eccentricity from 0.7 (with a bearing length to diameter ratio of 1.25) to 0,8 (with a bearing length to diameter ratio of 0.8 ), which ensured the diameter of the installation diameters in $0.1 \ldots$ $0.123 \mathrm{~mm}$ and determined the characteristic changes in the remaining parameters.

The results of the hydrodynamic calculation of bearings influence the differences in the characteristics of the proposed materials of surface coatings (except for the parameters of boundary friction) is insignificant, and the deviations from the geometry of the bearing surfaces and the degree of oil filtration are incorporated into the minimum working gap [12].

Therefore, the parameters of the hydrodynamic mode of lubrication of bearings with the proposed antifriction materials for coating surfaces, calculated for the previously selected bearing diameter of the intermediate gear of the NMHMP motor gearbox $85 \mathrm{~mm}$ (in versions with five and six intermediate gears), are shown as the same for all proposed coatings, except for the parameters of boundary friction [3].

The length of the bearings with a diameter of $85 \mathrm{~mm}$, providing their estimated bearing capacity, depending on the minimum working clearance in accordance with Figure 6. 


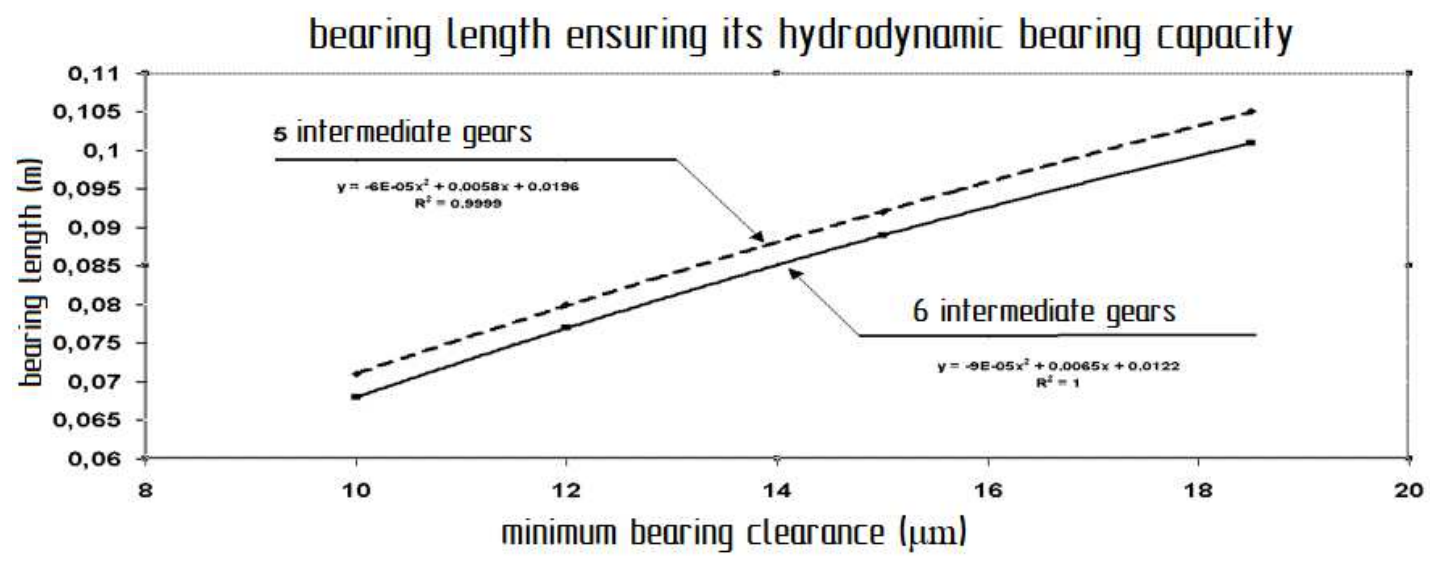

Figure 6. Bearing length depending on the minimum working clearance.

The maximum working pressure in the lubricant layer of bearings, depending on the minimum working gap and the corresponding length of the bearing, is shown in figure 7.

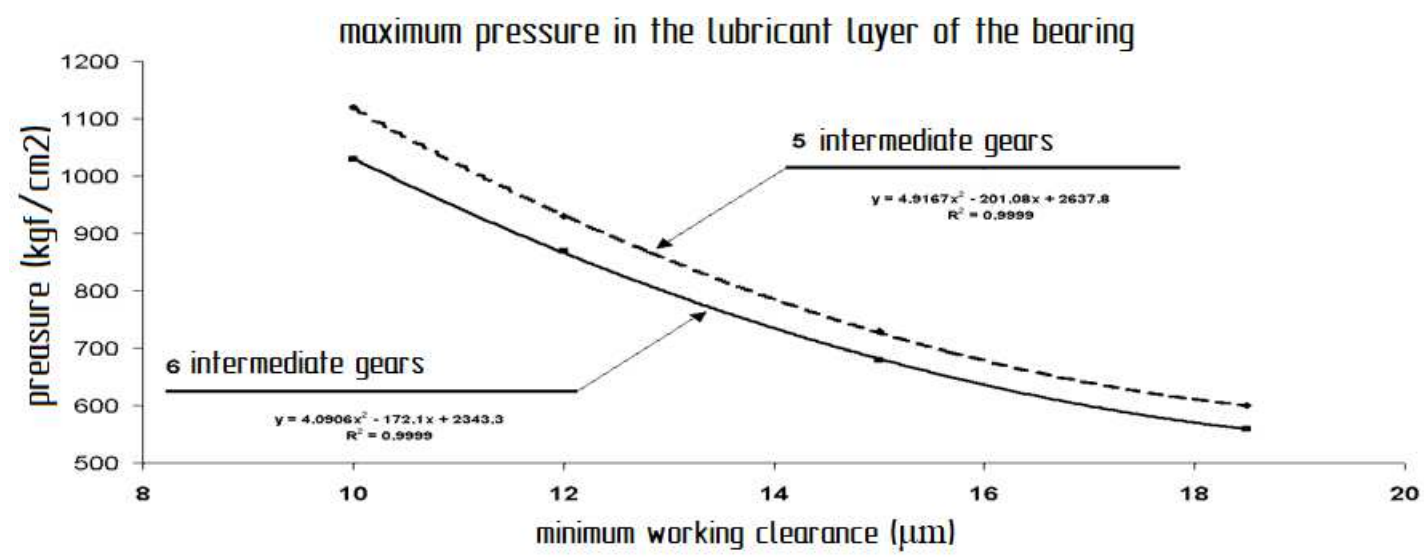

Figure 7. Maximum working pressure in the lubricant layer depending on the minimum working clearance and the corresponding length of the bearing.

The dependence of oil heating on viscous friction in bearings, depending on the minimum working gap and the corresponding bearing length, is shown in Figure 8.

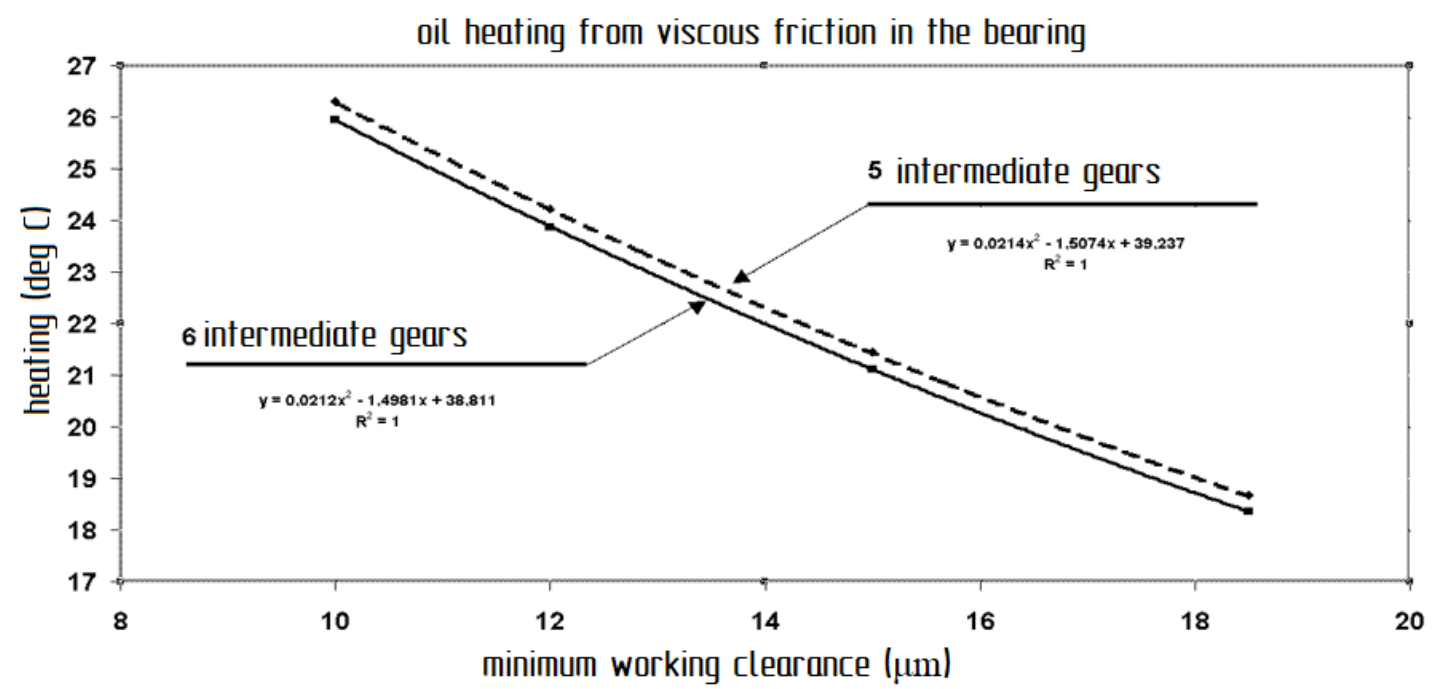

Figure 8. Heated oil from viscous friction, depending on the minimum working gap and the corresponding length of the bearing.

The parameters of the bearings with the proposed anti-friction coatings in the version of the gearbox for a NMHMP engine with five intermediate gears are shown in Table 2. 
Table 2. Bearing parameters for gearbox variant with five intermediate gears.

\begin{tabular}{|c|c|c|c|c|}
\hline \multirow[b]{2}{*}{ Bearing load $(w), \mathrm{N}$} & \multicolumn{4}{|c|}{ Parameter value } \\
\hline & 140019 & & & \\
\hline Rotation frequency $(n), \min ^{-1}$ & 11110 & & & \\
\hline Oil grade & MJO-II & & & \\
\hline Oil inlet temperature $(t b x),{ }^{\circ} \mathrm{C}$ & 100 & & & \\
\hline The angle of oil supply $(a l), C$ & 120 & & & \\
\hline The required oil pumping $(q), \mathrm{m}^{3} /$ hour & 0.567 & & & \\
\hline Bearing diameter $(d), \mathrm{mm}$ & 85 & & & \\
\hline Minimum working clearance $\left(h_{\min }\right), \mu \mathrm{m}$ & 18,5 & 15 & 12 & 10 \\
\hline Bearing length $(L), \mathrm{mm}$ & 105 & 92 & 80 & 71 \\
\hline Maximum pressure in the lubrication layer $\left(P_{\max }\right), \mathrm{MPa}$ & 58.84 & 71.6 & 91.2 & 109.8 \\
\hline Bearing operating eccentricity $(E$ & 0,7 & 0,733 & 0,77 & 0,8 \\
\hline The ratio of length to diameter $(L / d)$ & 1,238 & 1,084 & 0,939 & 0,835 \\
\hline Radial mounting clearance $\left(C_{m}\right), \mu \mathrm{m}$ & 61,6 & 56,1 & 52,1 & 50 \\
\hline The ratio of the radial clearance to the radius $\left(C_{m} / r\right)$ & 0,00145 & 0,00132 & 0,00123 & 0,00118 \\
\hline Viscous oil heating level (tbix), ${ }^{\circ} \mathrm{C}$ & 118,664 & 121,443 & 124,216 & 126,305 \\
\hline Temperature of onset of turbulence $(t k r),{ }^{\circ} \mathrm{C}$ & 134,4 & 144,389 & 152,92 & 158,092 \\
\hline \multirow{3}{*}{$\begin{array}{ll}\left(N_{r}\right) \text { Specific power at } & \text { Silicon carbide, } \mathrm{kW} / \mathrm{cm}^{2} \\
\text { boundary friction } & \text { Titanium carbonitride, } \mathrm{kV}\end{array}$} & 0,774 & 0,885 & 1,021 & 1,148 \\
\hline & 5,419 & 6,192 & 7,144 & 8,034 \\
\hline & 3,87 & 4,423 & 5,103 & 5,739 \\
\hline Sommerfeld number $\left(S_{0}\right)$ & 14,805 & 14,583 & 15,059 & 15,986 \\
\hline Loss of viscous friction $(N), \mathrm{kW}$ & 8,17 & 7,78 & 7,35 & 6,99 \\
\hline Arc lubrication $(T E)$ & 158,704 & 156,087 & 153,056 & 150,5 \\
\hline The stiffness of the layer of oil $(d w d h), \mathrm{N} / \mu \mathrm{m}$ & 16475 & 20005 & 24713 & 29420 \\
\hline
\end{tabular}

\section{Conclusion}

The application of the proposed anti-friction coatings for the surfaces of hydrodynamic bearings with technologically and operationally ensured reduction of the minimum operating clearance may allow a significant increase in the average specific bearing load and, thereby, reduce the axial dimensions of the bearings while simultaneously increasing the maximum pressures in the lubricating layer (see Figures 5, 6 and table 2), which in turn should be provided not only with the properties of coating materials, but also with the properties of materials of construction and the bearing design itself.

As can be seen from table 2, ion-vacuum coating materials based on silicon carbide has a clear advantage over the other proposed coatings under conditions of boundary friction (taken into account its minimum coefficient of friction is comparable to the coefficient of friction of fluoroplastic with grease on steel, and the coefficient of thermal conductivity is much higher than other proposed coating materials.

But, as experience shows, in order to successfully work out the parameters of promising heavily loaded hydrodynamic sliding bearings, a close relationship is needed between the calculated estimate and its experimental verification (while perfecting the tools and methods of both). [13]

As a result of this work, RKD was produced for sliding bearings with anti-friction coatings based on metal polymers, ceramic ceramics (silicon carbide, titanium diboride) with and without quasicrystals and composite materials (titanium carbonitride, silicon carbonitride) with and without quasicrystals.

\section{References}

[1] Pomogaylo A. D. Metal-polymer composites with controlled molecular architecture // Russian chemical journal.-2002 T. 46 № 5 P. 64-73.

[2] Elison V. M., Sleptsov V. V., Dmitriev S. N. Ion-plasma modification of the surface of polymeric materials for medicine and ecology is one of the most important areas of surface engineering // Technological equipment and materials, 1998. t. 2. P42-48.

[3] Konshin A. S., Gorlov E. A., Silchenko O. B. Angular contact ball bearing // Patent for invention RUS 2247876, 15.03.2002.

[4] Silchenko, OB, Siluianova, MV, Nizovtsev, V. E., Klimov, DA, Kornilov, A. A. On the prospects for the use of nanostructured heterophase polyfunctional composite materials in the aircraft engine industry // Materials Science. 2018. №1. Pp. 50-57.

[5] Sil'chenko O. B., Siluyanova M. V., Kuritsyna V. V. Diagnostics of Dimensionally Controlled Microgrinding to Meet Quality Specifications // Russian Engineering Research. 2018. T. 38. № 8. pp. 604-609.

[6] Sil'chenko O. B., Siluyanova M. V., Kornilov A. A., Maktykbekov B. Some models for estimating the stress-strain state of ceramic composite materials taking into account technological pores. // Bulletin of the Bryansk Technical University. 2018 №1, ss 94-101.

[7] Sil'chenko O. B., Siluyanova M. V., Nizovtsev V. E., Klimov D. A., Polev A. S. On the prospects for the use of nanostructured heterophase polyfunctional composite materials in engine building // Materials Science Issues, №1, 2018, pp. 50-58. 
[8] Piskarev A. A., Kuritsyna V. V., Siluyanova M. V., Silchenko O. B., Analysis of design solutions used in the design of highloaded sliding bearings with liquid lubricant // Vestnik Mashinostroeniya, № 5, 2018 g., Ss...179-191.

[9] Piskarev, AS, Silchenko, OB, Nizovtsev, V. E., Siluyanova, MV, Kuritsyna, V. V. Investigation of a heavy-loaded hydrodynamic sliding bearing of a TRDD gearbox of a new generation for BSMS of civil aviation // Bulletin of the Bryansk State Technical University, No. 5, 2018, pp. 141-153.

[10] Siluyanova M. V., Kuritsyna V. V., Silchenko O. B. Automation of technological expertise in making production decisions // Automation. Modern technologies, No. 5, 2018, pp. 199-207.

[11] Silchenko, OB, Fokin, AS Analysis of design and technological capabilities for the production of plain bearings with antifriction coatings based on metal polymers, ceramic polymers or composite materials using quasicrystals // Proceedings of theses of the XLIV reports of the International Youth Scientific Conference "Gagarinsky Readings" April 18, 2018, Moscow, Moscow: MAI, 1918 city, ss. 216-218.

[12] Silchenko O. B., Khamzatkhanov S. S. Development of technology for creating an output device with a low noise level from high-temperature metal-ceramic composite materials (VMKM) // Collection of Abstracts of Reports of the XLIV International Youth Scientific Conference "Gagarinsky Readings" April 18, 2018, Moscow, Moscow: MAI, 1918 ss. 219-220.

[13] Sil'chenko O. B., Siluyanova M. V. Investigation of mechanical and tribological properties of coatings made of composite materials reinforced with quasicrystals obtained by the method of cold gas-dynamic spraying // Bulletin of the Bryansk State Technical University, No. 5, 2018, pp. 16-18. 